\title{
Sylvie Fainzang e a "Cultura da Abstinência"
}

FAINZANG, Sylvie.

Curar-se do álcool: antropologia de uma luta contra o alcoolismo.

Niterói: Intertexto, 2007. 105 p.

| Fernanda Vecchi Alzuguir |

Mestre e Doutoranda em Saúde Coletiva pelo IMS-UERJ. Endereço eletrônico: fevecchi@ims.uerj.br

O livro Curar-se do álcool: antropologia de uma luta contra o alcoolismo, da antropóloga francesa Sylvie Fainzang, é uma contribuição significativa para os estudos do álcool e do alcoolismo. A publicação desse trabalho no Brasil divulga uma das poucas obras da área socioantropológica que realiza uma reflexão densa e criteriosa sobre os mecanismos simbólicos de gestão do alcoolismo. ${ }^{1}$ Trata-se de uma coletânea de textos publicados em revistas francesas, que têm como objetivo comum a análise do sistema de significações e condutas do movimento "Vie Libre"- um grupo francês formado por ex-bebedores e seus cônjuges. Fainzang empreende um estudo etnográfico da luta contra o alcoolismo travada por aquele movimento, caracterizado como uma verdadeira "cultura da abstinência", ou seja, um sistema de valores específicos relativos à gestão do alcoolismo para pessoas que se consideram doentes.

A delimitação do objeto de estudo, já nas primeiras páginas do livro, ilustra sua originalidade. Tanto o prefácio - da antropóloga brasileira Delma Pessanha, outra importante estudiosa do campo - quanto seu capítulo introdutório despertam o leitor para uma abordagem singular sobre os temas do álcool e do alcoolismo.

A proposta de uma etnografia da "cultura da abstinência" representa mais do que uma simples transposição de conteúdo temático das práticas sociais de alcoolização para as práticas de evitação do álcool. Ela inaugura uma forma de apreensão do álcool e do alcoolismo como objetos de análise. Assim, a pesquisadora se contrapõe em aspectos importantes às afirmações da antropóloga inglesa Mary Douglas (1987), elaboradas na obra Constructive drinking: perspectives on drink from anthropology, um marco na literatura antropológica sobre o álcool. ${ }^{2}$ No esforço de delimitar o campo da antropologia e diferenciá-lo das outras disciplinas que 
investigam o tema do álcool, como a sociologia e a epidemiologia, Douglas alerta para a necessidade da adoção, pelos antropólogos, de uma perspectiva específica sobre o álcool: recusar a noção (histórica) de "doença alcoólica" e, consequentemente, o pressuposto do consumo de álcool como um traço patológico. Desse modo, recomenda que tal consumo seja encarado como uma prática constitutiva do vínculo social, um modo de vida ou um traço da cultura. A antropóloga inglesa chama a atenção ainda para os cuidados de se preservar o ponto de vista nativo a respeito do uso de álcool, como uma forma de o pesquisador não reproduzir a visão (etnocêntrica) do álcool como um problema. É sobre este último ponto que incide a objeção de Fainzang: considerar o discurso nativo sobre o álcool pode consistir justamente em reter a equivalência entre alcoolismo e doença, sem significar, entretanto, a reprodução das categorias médicas.

A singularidade dessa verdadeira cultura que se constrói em torno da abstinência como terapia e como valor (e, portanto, como modo de gestão da vida, indissociável de um contexto patológico) fundamenta a afirmação de que sua análise está menos próxima do campo da "antropologia do beber" do que da "antropologia da doença". Essa aproximação é fundamentada a partir do objetivo de sua pesquisa, qual seja, a compreensão das condutas e valores de pessoas que se consideram doentes em relação ao álcool. Outra possibilidade de contextualizar aquela aproximação é a partir do próprio itinerário de pesquisa da autora e das indagaçôes dele decorrentes. Uma interrogação comum que perpassa seu itinerário de pesquisa é o interesse pela relação entre a interpretação da doença e seus modos de agenciamento em um dado contexto social. ${ }^{3}$ A antropóloga destaca a temática da construção social da doença como uma importante grade de leitura das relaçóes sociais em contextos tidos como "exóticos" - como no estudo que realizou com os "burkina faso", na África - e ocidentais - como no caso do grupo "Vie Libre". Neste último exemplo, a terminologia que melhor se aproxima de tal campo de análise é o que a autora cunhou de "antropologia do déboire", ${ }^{4}$ cuja melhor tradução para o português talvez seja "antropologia do não-beber".

O livro se divide em oito seções. Cada uma delas descortina um aspecto da cultura multifacetada do movimento "Vie Libre". Uma visão panorâmica sobre o conteúdo de cada seção pode ajudar a compreensão dos múltiplos aspectos daquela cultura. A introdução inaugura um fecundo debate que tem como fio condutor a delimitação do objeto e do campo mais amplo da pesquisa. A seção 2 apresenta os 
princípios e valores que fundamentam o grupo "Vie Libre". Sua doutrina consiste na estruturação de uma teoria da doença alcoólica e dos objetivos do movimento, quais sejam, a cura e a luta contra as causas do alcoolismo. Os membros são em grande parte provenientes das camadas populares. Os "bebedores curados" são exbebedores que se livraram da doença, apoiando-se na total abstinência do álcool. Por sua vez, os "abstinentes voluntários" são, em sua maioria, os cônjuges dos bebedores, que optam pela abstinência em solidariedade aos doentes. Já os "simpatizantes" são membros que aderiram à causa do movimento, embora não precisem observar a regra da abstinência. $\mathrm{O}$ álcool é percebido, antes de tudo, como um mal social, corroborado pelas condiçōes de vida de um grande número de indivíduos e pelos interesses econômicos que regem sua produção e consumo. O bebedor é considerado uma vítima ou um escravo acorrentado a esse mal. Assim, a cura do alcoolismo se assemelha a uma libertação, sendo a luta contra o álcool um "combate social". A militância consiste basicamente em visitas a hospitais, escolas e prisões, objetivando não só o apoio e a informação, mas também o recrutamento de novos membros.

Destaca-se uma diferença importante da teoria da doença elaborada pelo grupo francês, em relação à doutrina do conhecido grupo "Alcoólicos Anônimos" (AA): enquanto que para o AA o alcoolismo é genético e, portanto, incurável, para "Vie Libre" ele é adquirido, sendo passível de cura. Neste caso, a aceitação da cura não entra em contradição com a defesa da abstinência como terapêutica e como valor. O alcoolismo é comparado a uma bronquite: o fato de ser curável não impede a manutenção de certos cuidados pelo doente para que a doença não retorne. Portanto, mesmo que as duas associações sejam unânimes quanto à afirmação do alcoolismo como uma doença, elas diferem sobre o tipo de doença a respeito da qual se discute.

A seção 3 evidencia de que forma a identidade e o anonimato estão no cerne dos mecanismos simbólicos de validação da necessidade da abstinência junto aos membros. Isto é ilustrado pelo rito de entrega do "cartão rosa", que confere ao membro a identidade de "bebedor curado", o que o torna, a partir de então, apto para exercer uma série de direitos e deveres no grupo. É através da fabricação da identidade do "bebedor curado" que o grupo efetua a adesão dos indivíduos à sua cultura.

A seção 4 analisa as concepções etiológicas elaboradas pelos membros do movimento a respeito do alcoolismo e ilustra a afinidade do estudo com o campo da "antropologia da doença". Atestando a profusão de sentidos em circulação na cultura 
"Vie Libre", a autora observa a convivência de discursos antagônicos no interior do grupo: o discurso doutrinal e o individual. O primeiro é um discurso coletivo e relativamente homogêneo, que aparece nas publicaçôes do movimento. Já o discurso individual é heterogêneo, e remete às visões do alcoolismo particular, ou seja, da forma como ele é experimentado por cada membro do grupo. A coexistência dos dois tipos diferentes de discurso é assegurada por um consenso mínimo: a responsabilização do álcool-sujeito como causalidade última da doença. Observa-se aqui outra qualidade da maneira como a pesquisadora analisa seu objeto: o respeito a modos singulares de interpretação e agenciamento da doença alcoólica, não necessariamente compatíveis com a teoria do movimento. A valorização - e a nãoresolução - da tensão entre as dimensôes contrastantes dentro de uma mesma cultura condiz com a postura teórico-metodológica da antropóloga, justificada na publicação original. ${ }^{5} \mathrm{Na}$ referida obra, a antropóloga afirma sua escolha de se posicionar propositalmente a meio caminho entre as abordagens estruturalistas e as da sociologia da ação, não se colocando, assim, a favor da supremacia de nenhum dos dois termos da polaridade indivíduo/sociedade. Dessa forma, ela opta por uma concepção de sujeito que se constitui na inter-relação entre essas duas categorias, como explica na seguinte afirmação: "L' individu est donc um sujet, au sens où il est à la fois auteur [...] de sés actes, et inféodé aux déterminants sociaux et culturels" (1998, p. 13). ${ }^{6}$

Outro aspecto relevante é a influência das "categorias de sexo" na construção das causalidades individuais. No discurso da causalidade alcoólica, um interessante padrão é verificado: o lugar acordado ao meio familiar e ao hábito, quando se trata do alcoolismo dos homens, e à depressão e outras dificuldades psicológicas, no caso do alcoolismo feminino. Há uma tendência de se antecipar causas psicológicas para explicar o alcoolismo da mulher, contrapondo-se à evocação de causas sociológicas para o alcoolismo do homem. A análise desse padrão discursivo é instigante por evidenciar os aspectos culturais em jogo na construção da diferença entre o alcoolismo masculino e feminino. Assim, se por um lado a causa do alcoolismo é situada no interior da mulher, por outro, ela é externa ao homem. Isso evidencia o pressuposto cultural de que as mulheres são naturalmente vulneráveis ao álcool.

Esta última questão transparece no comentário da autora sobre a curiosa inversão da relação de causa e efeito entre os temas do estado dos nervos e do alcoolismo, de acordo com o gênero. Assim, enquanto que para a maioria - homens e mulheres são os nervos que propiciam a alcoolização excessiva de mulheres, no caso dos 
homens, é a alcoolização excessiva que suscita a fragilização dos nervos. Esse tipo de construção remete à suposição de uma natureza feminina mais vulnerável e potencialmente doente, ao passo que, para o homem, é a natureza corruptível do álcool que provoca a fragilização dos nervos. Também são observadas estratégias de ocultamento das causas psicológicas do alcoolismo masculino. Exemplificando esse fato, os poucos bebedores que evocam dificuldades psicológicas referem-se frequentemente a uma "boa razão" para tal, como uma "injustiça” sofrida. Essa passagem do seu trabalho comprova a íntima conexão entre os domínios da construção social do alcoolismo e do gênero. Infelizmente, a autora não aprofunda essa análise, o que seria uma via bastante rica, considerando-se a escassez de trabalhos sobre gênero e alcoolismo no campo dos estudos sobre o álcool. Portanto, a antropóloga apenas sinaliza algumas trilhas de análise que carecem de uma reflexão teórica mais densa, como, por exemplo, um diálogo mais estreito com a literatura socioantropológica sobre gênero.

As seções 5 e 6 trazem para o centro do debate o tema mais amplo das percepções sobre o corpo do alcoólico. Os discursos que os cônjuges e ex-bebedores constroem sobre o alcoólico variam de acordo com a experiência de cada um em relação à doença. Se os ex-bebedores experimentaram o álcool em seus corpos, os cônjuges o fizeram "na relação" com o outro. Mas ambos os olhares têm em comum a percepção de uma "perda da humanidade" em função do álcool. Em síntese, os olhares convergem para a definição do alcoólico como aquele cuja "natureza" foi invertida, mas de um modo negativo. O álcool pode ser assim identificado como uma substância de conversão de uma identidade para uma alteridade. Conclui-se que o bebedor deixa de ser um consumidor para ser um alcoólico, quando ocorre a passagem do estado "humano" (ou cultural) ao estado "não humano" (ou estado de natureza).

Essa questão abre uma via de interpretação do álcool pela antropologia explorada na seção 5 - que é a de pensá-lo como um importante signo que marca a transição entre os registros da cultura, da natureza e do sobrenatural. ${ }^{8}$ Em última instância, evidencia-se o papel da cultura na definição dos parâmetros de normalidade e desvio, e dos limites que separam o consumidor normal do alcoólico. Dessa forma, o traço patológico é fixado naqueles que se desviam do cumprimento de um papel social adequado. A totalidade dos traços que se vinculam ao alcoólico o transporta a uma outra idade, biológica e social (o mundo da infância ou da velhice), e também a um outro reino, vegetal ou animal. Fainzang observa uma 
tendência de aproximação da figura da mulher alcoólica ao reino vegetal, através de descrições sobre a mudança de seu comportamento no sentido da passividade. Assim, essa passividade da mulher alcoólica, avaliada negativamente, denota seu distanciamento de uma função feminina esperada, como se verifica no relato de um cônjuge sobre a mudança de comportamento de sua esposa: "Ela tinha se tornado má. A maldade podia ser vista em seu olhar, é isso. Além disso, ela dormia. Era passiva com relação a tudo. E isso era uma catástrofe, mesmo na cama ela era passiva! [...] Ela já não tinha mais vida!" (p. 59). Este é um bom exemplo do impacto da dimensão do gênero na seleção de diferentes parâmetros de normalidade para homens e mulheres. Atesta-se, mais uma vez, a importância de se aprofundar essa temática e sua articulação com a construção social do alcoolismo.

A seção 6 discute as representações dos cônjuges e ex-bebedores sobre os efeitos do álcool em seus corpos. Os nervos, o sangue e o cérebro se destacam como os alvos privilegiados do álcool. As desordens fisiológicas do álcool no corpo remetem à percepção do comportamento social do alcoólico e da relação com o outro. Baseando-se nas definições de Mary Douglas sobre o corpo, Fainzang mostra, a partir da análise dos discursos, de que maneira o corpo exprime uma realidade social. Ele simboliza a vida social e relacional do bebedor, ao mesmo tempo em que encarna as desordens que se realizam nessas duas dimensões. As máculas do sangue expressam a desordem fisiológica, enquanto a perturbação dos nervos (exemplificada pela agressividade e pela instabilidade do humor) sinaliza a desordem relacional. Já a lesão do cérebro traduz a desordem no tocante ao mundo exterior (incapacidade de trabalhar, por exemplo).

A penúltima seção do livro discorre sobre os sentidos em relação à abstinência e à dependência. Congruente com sua atitude analítica de valorização da particularidade do sistema simbólico dos grupos de enfrentamento do alcoolismo, Fainzang questiona o estabelecimento apressado de semelhanças entre culturas distintas. A valorização da especificidade do "Vie Libre" leva à argumentação sobre o equívoco de se compreender a cultura da abstinência como o inverso da cultura da alcoolização, como se os valores pudessem ser invertidos ponto-aponto, numa espécie de inversão simétrica. Assim, a autora descreve: "Não há apenas inversão, ou seja, o consumo de bebidas sóbrias não inverte a significação do consumo de álcool. Ele faz parte de um outro registro, marcando uma ruptura na ordem das significações". (p. 86). 
Por fim, a última seção dedica-se à análise das representações dos cônjuges dos ex-bebedores a respeito do alcoolismo. Esses membros reivindicam o estatuto de doente, através da afirmação de um contágio do alcoolismo do(da) companheiro(a) para si. Assim, evidenciam uma concepção de contágio interessante do ponto de vista antropológico, considerando seu distanciamento em relação à definição médica. Para os cônjuges, a proximidade física e social ocasionada pelos laços do matrimônio é o que promoveria tal contaminação. A ideia de contágio é uma via de acesso à percepção do impacto do alcoolismo sobre o outro ou de sua dimensão relacional.

As seçōes do livro de Fainzang comprovam o caráter multifacetado da cultura "Vie Libre". A etnografia de uma cultura que gravita em torno da ideia da abstinência como um valor - cujos significados dão sentido àquelas pessoas que acreditam ser marcadas ou atingidas ${ }^{9}$ por uma doença - mostra uma apreensão original do tema do alcoolismo. Seu trabalho é um exemplo de que é possível "valorizar" a ligação que os membros do grupo estabelecem entre alcoolismo e doença, sem no entanto defendê-la. A autora também mostra que a atribuição de uma marca patológica ao uso do álcool não é sinônimo de adesão ao ponto de vista médico. Pensar assim seria subestimar a capacidade dos sujeitos de construírem uma teoria particular da doença, mesmo que a partir da reformulação de aspectos do saber médico. Alguns capítulos enfatizam a dimensão relacional do álcool, como no caso da definição da transmissão do contágio alcoólico pelos cônjuges, a partir dos laços simbólicos do matrimônio e da proximidade física. A análise dos efeitos e das causas do álcool também evidencia seu aspecto relacional, que denota a inscrição dessa substância em um contexto sociocultural.

A dimensão relacional do alcoolismo pode ser analisada à luz do modelo físicomoral da perturbação dos nervos, proposto por Duarte (1988) em seu estudo das representações de classes trabalhadoras sobre o "nervoso" ${ }^{10} \mathrm{Na}$ perspectiva desse autor, a ideia de perturbação relativiza os reducionismos fisicalistas relacionados à representação da "doença”. Sob os auspícios da biomedicina, essa representação só adquire sentido no interior da configuração individualista moderna, que visa a neutralizar a dimensão moral da análise (1998). O estudo do alcoolismo evidencia a possibilidade de entendê-lo como uma perturbação físico-moral, pois a análise dos discursos dos membros do movimento "Vie Libre" ilumina de que forma os aspectos morais estruturam a construção do alcoolismo como uma doença. 
As representações dos efeitos do álcool sobre o corpo do alcoólico, por exemplo, ilustram que o limite entre um consumidor e um "alcoólico" repousa em julgamentos sociais sobre o desempenho de funções esperadas para um homem e uma mulher "responsáveis". Tudo aquilo que não se inscreve neste registro, como a perda da capacidade de autocontrole, reinscreve-se sob o crivo da patologia. A dimensão do gênero ou, na terminologia francesa, as "categorias de sexo", também apontam para a presença dos aspectos morais na organização da teoria da doença alcoólica pelo "Vie Libre". Assim, na elaboração das causas do alcoolismo, a referida dimensão influencia na atribuição de causas psicológicas para a mulher e de causas sociológicas para o homem. Por sua relevância, o papel das relaçôes de gênero na estruturação dos discursos sobre a doença é um tema que ainda precisa ser mais bem explorado no campo da antropologia do álcool. ${ }^{11} \mathrm{~A}$ análise de Fainzang demonstra a possibilidade do estudo do alcoolismo pela antropologia como uma via significativa de compreensão da organização social (do mesmo modo que ocorre com categorias como corpo, sexo e gênero).

Por todas essas razões, somadas à constituição recente desse campo de pesquisa e à forma singular com que a autora aborda o tema do alcoolismo, o livro de Sylvie Fainzang é uma contribuição relevante para os estudos socioantropológicos sobre o álcool.

\section{Referências}

ALZUGUIR, Fernanda de C. V. A desculpabilização pela doença: o alcoolismo no discurso de mulheres alcoólicas. 2005. 155 p. Dissertação (Mestrado em Saúde Coletiva) - Instituto de Medicina Social, Universidade do Estado do Rio de Janeiro, Rio de Janeiro, 2005.

DUARTE, Luiz Fernando D. Da vida nervosa nas classes trabalhadoras urbanas. 2. ed. Rio de Janeiro: Zahar, 1988. 290 p.

. Investigação Antropológica sobre doença, sofrimento e perturbação: uma introdução. In: DUARTE, L.F.; LEAL, O. F. (Orgs.). Doença, sofrimento, perturbação: perspectivas etnográficas. Rio de Janeiro: Fiocruz, 1998. p. 9-27.

FAINZANG, Sylvie. Ethnologie des anciens alcooliques. La liberté ou la mort. 2. ed. Paris: Presses Universitaires de France, 1998. 171 p.

. Entre práticas simbólicas e recursos terapêuticos: as problemáticas de um itinerário de pesquisa. Antropolítica, Niterói, n. 15 (2. sem.), p. 39-59, 2003. 


\section{Notas}

${ }^{1}$ Referência à publicação francesa: Ethnologie des anciens alcooliques. La liberté ou la mort. Paris: Presses Universitaires de France (FAINZANG, 1998).

${ }^{2}$ Cabe ressaltar que a obra de Douglas foi uma das primeiras tentativas de reflexão sobre o papel da antropologia no estudo do álcool. É, portanto, uma leitura fundamental para os pesquisadores interessados neste assunto.

${ }^{3}$ Em um artigo de 2003, Fainzang descreve as problemáticas construídas em distintos contextos de pesquisa, as diferenças e a articulação entre elas.

${ }^{4} \mathrm{O}$ texto de Fainzang (1998) mantém a palavra em francês e explica, em uma nota de rodapé (p. 15), os dois sentidos possíveis, em francês, ao termo "déboire": 1) gosto desagradável deixado na boca por uma bebida alcoólica e 2) sensação penosa resultante do sentimento de decepção. Além destes sentidos, o prefixo de negação "de" em "dé-boire" remete à expressão "não beber".

${ }^{5}$ Ver nota de rodapé $n^{\circ} 2$.

6 "O indivíduo é, portanto, um sujeito, no sentido dele ser tanto o autor (...) dos seus atos quanto submetido aos determinantes sociais e culturais". [tradução nossa].

${ }^{7}$ A tradução é fiel à terminologia francesa "catégorie de sexe”, utilizada pela pesquisadora e também por outros estudiosos franceses (juntamente com o termo "rapport de sexe") para designar o que a literatura anglo-saxã denomina de "gênero" ou, ainda, "relações de gênero". A opção por privilegiar, nesta resenha, as duas últimas denominações, se explica pela maior familiaridade em relação ao seu emprego na literatura brasileira sobre o assunto.

${ }^{8}$ Este último registro é ilustrado em contextos não-patológicos (em sociedades indígenas, por exemplo), onde o consumo de álcool organiza-se ritualisticamente como uma via de acesso a um estado suprahumano.

${ }^{9}$ Fainzang (1998) observa uma diferença de formulação da experiência da doença nos discursos dos cônjuges e ex-bebedores. Enquanto os primeiros se percebem e se sentem "marcados" pelo alcoolismo (pela aproximação física e social), os últimos são "atingidos" pelo alcoolismo (referindo-se à ingestão direta do elemento patogênico).

${ }^{10} \mathrm{O}$ estudo de Duarte foi citado na seção 5 do livro de Fainzang (2007).

${ }^{11} \mathrm{O}$ papel das relações de gênero na organização dos discursos sobre o alcoolismo foi tratado em Alzuguir (2005). 